\title{
The Value of Speech-Language Pathologists in Concussion Management
}

\author{
Caroline J. Ketcham, $\mathrm{PhD}^{1}$ Melissa Bowie, MS ${ }^{2}$ Thomas A. Buckley, EdD ${ }^{3}$ Martin Baker, $\mathrm{MS}^{4}$ \\ Kirtida Patel, $\mathrm{MD}^{4}$ Eric E. Hall, $\mathrm{PhD}^{1}$ \\ ${ }^{1}$ Department of Exercise Science, Elon University, Elon, \\ North Carolina \\ ${ }^{2}$ Department of Speech Language Pathology, Moses Cone Health \\ System, Greensboro, North Carolina \\ ${ }^{3}$ Department of Kinesiology and Applied Physiology, University of \\ Delaware, Newark, Delaware \\ ${ }^{4}$ Department of Athletics, Elon University, Elon, North Carolina \\ Address for correspondence Caroline J. Ketcham, PhD, Department
of Exercise Science, Elon University, 2525 Campus Box, Elon, NC
27244 (e-mail: cketcham@elon.edu).
}

Curr Res Concussion 2017;4:e8-e13.

\author{
Abstract \\ Keywords \\ - speech-language \\ pathologists \\ - SLP \\ - concussion \\ management
}

Objective The goal of this article is to make a case for the value of a speech-language pathologist (SLP) to be considered for inclusion on a concussion management team in a consultant capacity and resource for student-athletes during the return-to-learn process particularly at the high school or collegiate level where they may already be on staff or affiliated. SLPs have the skills and expertise to address difficulties and provide structured strategies to address symptoms of a concussion that affect cognitive processing, attention, and focus which often are impacted during recovery from a concussion. These skills alongside an athletic trainer/school nurse will provide a mechanism for student-athletes to be monitored and have a resource through the return-to-learn and return-to-play process.
Improving policies and practices surrounding concussion management and interventions are important to student-athlete well-being. Student-athletes are a population who juggle both the responsibilities of academics and the responsibilities of being an athlete. At all levels academics are the priority from an institution perspective, however, for student-athletes, their performance on the field matches or outweighs their priority to perform in the classroom. A disruption to their delicately balanced priorities and fine-tuned schedules can be anxiety provoking to student-athletes.

Concussions are an injury that can cause significant disruption if even for a short period. Student-athletes are asked to cognitively rest for 24 to 48 hours after injury and physically rest until symptoms subside which is typically within 7 to 10 days but can be more. ${ }^{1-4}$ This disruption stops both their progress in the classroom and on the field and puts them into an injury which is often given a "wait and see" status. Research is beginning to assess the importance of active rehabilitation for symptoms management and recovery from a concussion. ${ }^{5-7}$ Also, recommended concussion management protocols follow a plan where a return-to-learn process occurs before returning to play (-Fig. 1). However, disruptions to focus, attention, concentration, and memory can greatly impact return-to-learn process. Providing student-athletes and their management team a resource to help with evidencebased strategies in the academic setting could be a great asset. ${ }^{8}$ Giving student-athletes things "to do" in the academic setting to help when progress seems challenging could be beneficial to their ultimate return and their mental well-being.

Speech-language pathologists (SLPs) are professionals who are an integral part of brain injury rehabilitation typically after an acute and traumatic injury. While it is uncommon for an SLP to be part of a traditional concussion management team, a recent article found that in a concussion clinic, the second most referrals for concussions after physical therapy (28\%) was speech therapy (23\%) followed by received

September 23, 2016 accepted after revision April 27, 2017
Dol https://doi.org/

10.1055/s-0037-1603645. ISSN 2368-0539.
Copyright (c) 2017 by Thieme Medical

Publishers, Inc., 333 Seventh Avenue, New York, NY 10001, USA. Tel: +1(212) 584-4662
License terms

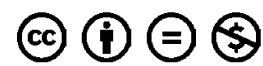




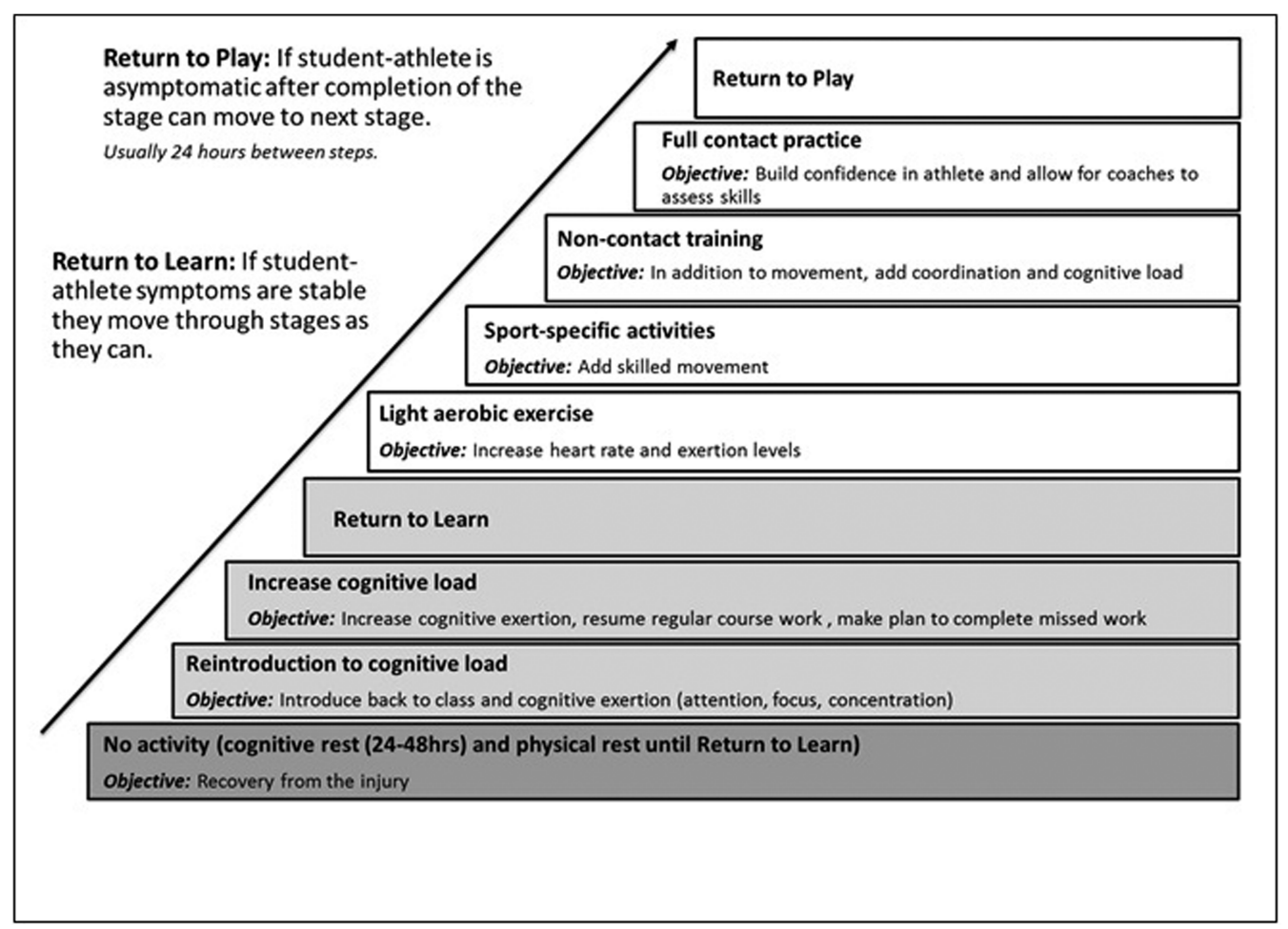

Fig. 1 Stages of return-to-learn and return-to-play for concussion management.

neuropsychology (10\%). ${ }^{9}$ This suggests that when available, an SLP is a valuable component of the concussion management team. This article will make the case that concussion management teams should consider including an SLP as part of their concussion management team in a consultant capacity and resource for student-athletes during the returnto-learn process. SLPs have the skills and expertise to help provide strategies to address the symptoms of concussions that affect cognitive processing, attention, and focus. Active rehabilitation is being considered to be worthwhile by leaders in the field, ${ }^{5-7}$ and SLPs may be a logical way to help scaffold active cognitive recovery following a concussive injury. ${ }^{5}$ Typical recovery time for concussions is 7 to 10 days with evidence that adolescents may take longer. ${ }^{1}$ In cases where concussion symptoms last more than 10 to 14 days, student-athletes are often referred to neuropsychologists or concussion specialists for comprehensive assessment and care. In some locations, this referral can take considerable time. Before this referral, student-athletes are usually already trying to return-to-learn in varying capacities. Including an SLP and providing strategic interventions earlier in the recovery process, giving student-athletes more support in the return-tolearn process, could lead to improvements in recovery time and return-to-play, as well as the quality of life.

\section{Defining Concussion and the Concussion Management Team}

A concussion is an injury that follows an indirect or direct force to the head that results in changes in brain function including measures of neurologic and cognitive dysfunc- tion. ${ }^{1-4,10}$ After the diagnosis of a concussion, the cornerstone of treatment is rest with cognitive rest recommended for 24 to 48 hours following injury, and physical rest is recommended until symptoms subside. ${ }^{1,3}$ It is believed that most patients will spontaneously recover in 7 to 10 days and those over this that have persistent symptoms should be a handled by a multidisciplinary team with experience in sports-related concussion. ${ }^{1,3}$ Up until this time (10-14 days postdiagnosis) at the collegiate level, the management of concussion has likely been handled by athletic trainers (AT) and team/personal/emergency medical personnel (e.g., physician, physician assistant). At the highschool level management varies greatly and may or may not have a school nurse or AT involved (i.e., only $38 \%$ of high schools have full-time access). ${ }^{11}$ If symptoms are still prevalent after the 10 to 14-day mark, student-athletes may be referred out to specialists or concussion clinics. Concussion clinics are multidisciplinary teams which may include specialists such as neurologists, neuropsychologists, physical therapists, occupational therapists, optometrists, and SLPs. These personnel all have a distinct set of skills that can be utilized to help the student-athlete to recover from injury. These clinicians will also often work continually in conjunction with the medical team on campus (AT; MD/DO; school nurse) and may also extend to academic counselors, the office of disability services representatives, and possibly teachers/faculty when discussing return-tolearn ( - Table $\mathbf{1}){ }^{8}$ Overall this multidisciplinary team is a concussion management team and their collaboration, communication, and ability to serve as a resource to the studentathlete and their support system is valuable to recovery and 
Table 1 Potential members of concussion management team

\begin{tabular}{|c|c|c|c|}
\hline Specialty & Primary role & When & Primary goals \\
\hline Athletic trainer & $\begin{array}{l}\text { Medical management/ } \\
\text { case management }\end{array}$ & $\begin{array}{l}\text { From initial injury through return-to- } \\
\text { play and return-to-learn; usually in } \\
\text { collegiate setting }\end{array}$ & $\begin{array}{l}\text { - Assess and treat symptoms and } \\
\text { return Student-Athlete to play } \\
\text { - Most common in collegiate setting }\end{array}$ \\
\hline $\begin{array}{l}\text { Team physician/ } \\
\text { neurologist }\end{array}$ & Medical oversight & $\begin{array}{l}\text { From initial injury through return-to- } \\
\text { play and return-to-learn; constant } \\
\text { contact with athletic trainers or nurse } \\
\text { depending on setting }\end{array}$ & $\begin{array}{l}\text { - Treat/manage medical issue } \\
\text { - Assess medical recovery/rehab }\end{array}$ \\
\hline Neuropsychology & $\begin{array}{l}\text { Cognitive and } \\
\text { behavioral assessment }\end{array}$ & $\begin{array}{l}\text { Usually referred to if symptoms } \\
\text { persist beyond } 10-14 \text { days }\end{array}$ & $\begin{array}{l}\text { - To assess deficits/rehab } \\
\text { progression/recovery of cognitive } \\
\text { and behavioral skills }\end{array}$ \\
\hline School nurse & $\begin{array}{l}\text { Medical management/ } \\
\text { case management }\end{array}$ & $\begin{array}{l}\text { From initial injury through return-to- } \\
\text { play and return-to-learn; role usually } \\
\text { most often in a high-school setting }\end{array}$ & $\begin{array}{l}\text { - Comfort and management of } \\
\text { medical needs } \\
\text { - In a high-school setting, this may } \\
\text { be the case management contact }\end{array}$ \\
\hline Academic advisor & $\begin{array}{l}\text { Academic } \\
\text { management/case } \\
\text { management }\end{array}$ & $\begin{array}{l}\text { From initial injury through return-to- } \\
\text { learn; continue follow-up with } \\
\text { student-athlete and instructors }\end{array}$ & $\begin{array}{l}\text { - Provide information to instructors } \\
\text { on return-to-learn progression } \\
\text { - Help coordinate make-up of missed } \\
\text { work }\end{array}$ \\
\hline $\begin{array}{l}\text { Speech-language } \\
\text { pathologist }\end{array}$ & $\begin{array}{l}\text { Receptive and } \\
\text { expressive cognitive and } \\
\text { speech skills }\end{array}$ & $\begin{array}{l}\text { May serve as a resource in the short- } \\
\text { term for return-to-learn; more in- } \\
\text { volved after if cognitive skills do not } \\
\text { recover }\end{array}$ & $\begin{array}{l}\text { - To manage speech, language, and } \\
\text { cognitive skills that may impact } \\
\text { various environments }\end{array}$ \\
\hline Physical therapist & $\begin{array}{l}\text { Gross motor skills/ } \\
\text { orthopedic needs }\end{array}$ & $\begin{array}{l}\text { May serve as a resource in the } \\
\text { short-term for return-to-play; more } \\
\text { involved if other injuries }\end{array}$ & $\begin{array}{l}\text { - To regain sport specific skills or } \\
\text { strength }\end{array}$ \\
\hline $\begin{array}{l}\text { Disability services/ } \\
\text { resource specialist }\end{array}$ & Academic difficulties & $\begin{array}{l}\text { May serve as a resource in the } \\
\text { short-term for return-to-learn; may } \\
\text { need to be more involved if return-to- } \\
\text { learn is compromised for more than } \\
\text { the } 10-14 \text { days }\end{array}$ & $\begin{array}{l}\text { - To help provide adaptive needs } \\
\text { or resources in the learning } \\
\text { environment } \\
\text { - Maybe a } 504 / \text { individualized } \\
\text { education programs plan for K-12 } \\
\text { school setting } \\
\text { - May be registered with disability } \\
\text { services for collegiate setting }\end{array}$ \\
\hline
\end{tabular}

reentry into the classroom at a minimum and hopefully back to full activity and the field of play.

\section{Role/Expertise of SLP in Concussion Management/Recovery}

One often overlooked profession to be included in a concussion management team is an SLP. The American SpeechLanguage Hearing Association (ASHA) identifies cognition to be within the scope of practice for SLPs resulting in some overlap with clinical neuropsychologists. ${ }^{12-16}$ Additionally, SLPs are licensed to evaluate and treat speech and language disorders while neuropsychologists are licensed to evaluate and treat mood disorders and emotional functioning. When considering the goal of student-athletes returning to academics and play, it is important to understand the differences and commonalities in practice patterns of both professions to allow for appropriate referrals and collaboration. The ASHA has identified how SLPs have the ability to complete brief, focused testing in the acute stages of recovery, more in-depth testing as cognitive recovery allows and refer/recommend neuropsychological evaluation at the appropriate time. ${ }^{14}$

SLPs with neurorehabilitation backgrounds have an understanding of typical cognitive processes and language domains and their interrelatedness. ${ }^{14}$ They are skilled at identifying impairments, making context based assessments, and providing scaffolded real-world activities that can be helpful during recovery. ${ }^{17}$ The insight gained from a functional task analysis can be beneficial for identifying effective short-term compensations and areas in need of rehabilitation. This is valuable information to consider when implementing return-to-learn protocols from an institutional or individual perspective.

Student-athletes use cognitive-linguistic abilities in and out of the classroom. Cognition encompasses arousal, attention, memory, reasoning, problem-solving, and executive functioning which may be influenced by a concussion. When identifying cognitive limitations or impairments a hierarchy is an effective way to identify where breakdowns occur (see -Fig. 2). Considering the attentional demands on an individual during the completion of a task is an important place to begin as it is necessary for all higher level cognitive-linguistic 


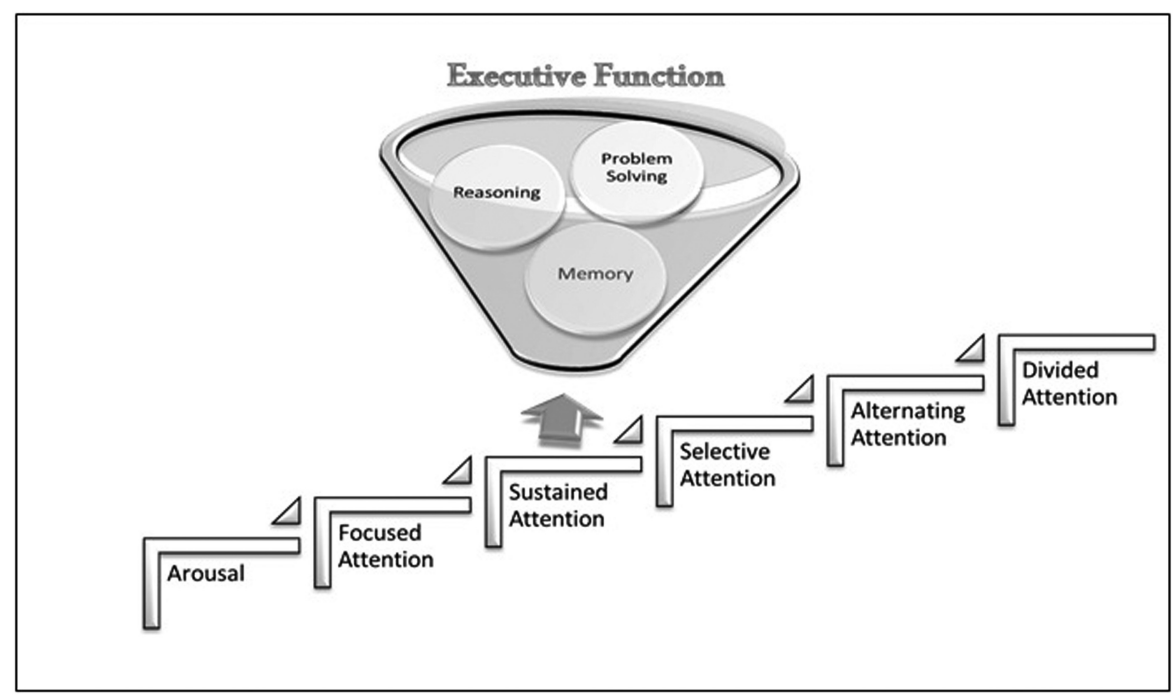

Fig. 2 Cognitive hierarchy. (Created by Heather Aalbers, MS, CCC-SLP, Kris Gellert, OTR/L, C/NDT, and Karen Pulaski, MS, OTR/L based on the work of Sohlberg and Mateer. ${ }^{18}$ )

abilities. Additionally, a working understanding of different levels of attention is an important place to start given that concentration difficulty is a common issue following concussion. ${ }^{12}$ For example, when asking a student to take notes during class they are being asked to listen to the speaker while simultaneously writing notes, this is considered a divided attention task. Following full cognitive rest, if attention continues to be an issue knowing where attentional breakdowns are occurring allows for modifications to be made. Also, it sets up a framework to use to facilitate returning to independence with tasks in an increasingly more "normal" setting (see - Table 2). ${ }^{18}$

Some other hallmark symptoms of concussion are headaches, confusion, slowed processing, and reaction to stimuli, dizziness, vision changes, and memory problems. These can also be impacted by task demand and environment and should be monitored, and modifications applied when needed. See $\mathbf{- T a b l e} \mathbf{3}$ for other modifications and treatments to consider when implementing return-to-learn protocols for student-athletes. In all cases, if symptoms are persisting for more than 2 weeks to a month, additional resources should be sought and consideration to include a 504 plan (high-school) or a disability plan (college) should begin if appropriate.

\section{Active Management of Return-to-Learn}

It is worth reiterating that return-to-learn is usually an ongoing process of introducing cognitive load after the initial rest. ${ }^{1,8}$ If symptoms are exacerbated with increasing load, then student-athletes are removed from that situation and told to try again later or for a shorter time. The recommendation is that once student-athletes return-to-learn, in a collegiate setting, the AT will then begin a return-to-play process which is adding in progressing physical activity and monitoring symptoms (-Fig. 1). In some cases, some early phases of return-to-play may happen during the return-to-learn process, but the priority should be to return to the classroom first.

Table 2 Levels of attention based on work of Sohlberg and Mateer ${ }^{18}$

\begin{tabular}{|c|c|c|c|}
\hline Attention level & Goal skill & Modification & Main ideas \\
\hline Divided attention & $\begin{array}{l}\text { Ability to respond to multiple } \\
\text { stimuli or tasks }\end{array}$ & $\begin{array}{l}\text { Writing notes while a professor } \\
\text { lectures }\end{array}$ & Highest level of attention \\
\hline Alternating attention & $\begin{array}{l}\text { Shifting attention between } \\
\text { two tasks }\end{array}$ & $\begin{array}{l}\text { Read a section, answer questions, } \\
\text { go back to reading, answer more } \\
\text { questions then return to reading } \\
\text { and so on }\end{array}$ & Able to use mental flexibility \\
\hline Selective attention & $\begin{array}{l}\text { Ability to ignore irrelevant or } \\
\text { distracting stimuli }\end{array}$ & $\begin{array}{l}\text { Reading in the library or listening to } \\
\text { a professor in a lecture hall with } \\
\text { typical environmental noise }\end{array}$ & \\
\hline Sustained attention & $\begin{array}{l}\text { Ability to work in a quiet } \\
\text { environment }\end{array}$ & $\begin{array}{l}\text { Reading or listening with no other } \\
\text { stimuli }\end{array}$ & $\begin{array}{l}\text { Need to have to use working } \\
\text { memory }\end{array}$ \\
\hline Focused attention & $\begin{array}{l}\text { Response to discrete visual, } \\
\text { auditory, or tactile stimuli }\end{array}$ & $\begin{array}{l}\text { Attending to your name being } \\
\text { called }\end{array}$ & Lowest level of attention \\
\hline
\end{tabular}


e12 SLP in Concussion Management Ketcham et al.

Table 3 Modifications for return-to-learn symptoms

\begin{tabular}{|l|l|l|l|}
\hline $\begin{array}{l}\text { Change/ } \\
\text { impairment }\end{array}$ & Student example & Modification & Treatment/Cognitive restructuring \\
\hline Visual & $\begin{array}{l}\text { Reading text or via computer } \\
\text { results in headaches }\end{array}$ & Audio recorded lectures & $\begin{array}{l}\text { Reading with large font in minimally } \\
\text { distracting visual feed for short periods }\end{array}$ \\
\hline Headaches & $\begin{array}{l}\text { Florescent lights trigger } \\
\text { headaches }\end{array}$ & $\begin{array}{l}\text { Modify learning environment } \\
\text { with lamps or natural light }\end{array}$ & $\begin{array}{l}\text { Education about and implementation } \\
\text { of checklist to increase awareness of } \\
\text { triggers which will empower student }\end{array}$ \\
\hline $\begin{array}{l}\text { Slowed } \\
\text { processing }\end{array}$ & $\begin{array}{l}\text { Cannot follow multi-step verbal } \\
\text { directions from professor or } \\
\text { coach }\end{array}$ & $\begin{array}{l}\text { Written multi-step instructions } \\
\text { or single step verbal directions }\end{array}$ & Structured tasks with time demands \\
\hline Memory & $\begin{array}{l}\text { Inability to recall new } \\
\text { information }\end{array}$ & Use of written aids & $\begin{array}{l}\text { Education regarding effective } \\
\text { compensatory strategies as well as } \\
\text { treatment of impaired attention which } \\
\text { impacts ability to store information }\end{array}$ \\
\hline
\end{tabular}

In a high-school setting, this may be less formalized or under the supervision of a physician off-site or a school nurse on the site since the presence of ATs in the high-school setting varies. $^{11}$ The problem with typical concussion management protocols may be that we introduce cognitive or physical load and remove if symptoms persist and maybe modifications to actively manage would be more effective.

Active rehabilitation is currently being assessed in larger clinical studies to determine if actively engaging studentathletes in specific tasks related to their symptoms helps them recover quicker. ${ }^{5-7}$ What we are suggesting is a similar scaffolded model to follow for targeting cognitive symptoms monitored by an AT or school nurse. One possibility is that can we speed up recovery by providing active management using more targeted support and structured strategies instead of using a passive management model where we reintroduce and remove as needed up to return-to-learn or referred out. This proactive stance after the immediate cognitive rest may help with recovery but will at least help relieve the impact on mental health of a "wait and see" strategy.

As we have described, an SLP can provide scaffolded activities related to attention, organization, and problemsolving skills, and provide further guidance in a consultation function if an individual is struggling to return-to-learn. ${ }^{12,13}$ Moving from a passive management to an active management focused plan may speed up recovery at best, and at worst give individuals tools to manage their new reality if symptoms persist. In the literature, there is a model of SLPs as an integral part of an assessment protocol and additional guidelines for recovery and referral of concussed individuals. ${ }^{13}$ SLPs may work closely with the ATs, school nurses, team physicians, or personal physicians to help the studentathlete return-to-learn, especially in a setting where SLPs are on staff (i.e., high schools, and colleges with SLP programs). The expertise of the SLP as it relates to return-to-learn would support the AT who is working with the student-athlete to make sure they are ready to return-to-play and not risk further injury. In addition to ATs not always being available, they do not have cognitive rehab expertise. Thus providing ATs, school nurses and/or physicians scaffolded activities for cognitive function and recovery could help in symptom monitoring and return-to-learn and return-to-play timing more effectively.

\section{Conclusion}

This article aimed to make the case that concussion management teams should consider including an SLP as part of their concussion management team especially in settings where an SLP is easily accessible (i.e., school setting, college settings with SLP programs). SLPs have been trained with strategies and interventions to target symptoms of concussions affecting executive function. The aim of including an SLP and providing intervention earlier in the recovery process is to support student-athletes and their concussion management team in the return-to-learn protocol leading to improvements in recovery time, return to full activity, as well as the quality of life and mental well-being.

\section{References}

1 McCrory P, Meeuwisse WH, Aubry M, et al. Consensus statement on concussion in sport: the 4th International Conference on Concussion in Sport held in Zurich, November 2012. Br J Sports Med 2013;47(05):250-258

2 McCrea M, Guskiewicz K, Randolph C, et al. Incidence, clinical course, and predictors of prolonged recovery time following sport-related concussion in high school and college athletes. J Int Neuropsychol Soc 2013;19(01):22-33

3 Giza CC, Kutcher JS, Ashwal S, et al. Summary of evidence-based guideline update: evaluation and management of concussion in sports: report of the Guideline Development Subcommittee of the American Academy of Neurology. Neurology 2013;80(24): 2250-2257

4 Harmon KG, Drezner J, Gammons M, et al; American Medical Society for Sports Medicine. American Medical Society for Sports Medicine position statement: concussion in sport. Clin J Sport Med 2013;23(01):1-18

5 Collins MW, Kontos AP, Okonkwo DO, et al. Statements of Agreement From the Targeted Evaluation and Active Management (TEAM) Approaches to Treating Concussion Meeting Held in Pittsburgh, October 15-16, 2015. Neurosurgery 2016;79(06):912-929 
6 Sawyer Q Vesci B, McLeod TC. Physical Activity and Intermittent Postconcussion Symptoms After a Period of Symptom-Limited Physical and Cognitive Rest. J Athl Train 2016;51(09):739-742

7 ClinicalTrials.gov. Role of rehabilitation in concussion management: a randomized controlled trial. ClinicalTrials.gov Identifier: NCT02988596. Available at: https://clinicaltrials.gov/ct2/show/ NCT02988596. Accessed February 1, 2017

8 Hall EE, Ketcham CJ, Crenshaw CR, Baker MH, McConnell JM Patel K. Concussion management in collegiate student-athletes: return-to-academics recommendations. Clin J Sport Med 2015; 25(03):291-296

9 Vargo MM, Vargo KG, Gunzler D, Fox KW. Interdisciplinary rehabilitation referrals in a concussion clinic cohort: An exploratory analysis. PM R 2016;8(03):241-248

10 Carney N, Ghajar J, Jagoda A, et al. Concussion guidelines step 1: systematic review of prevalent indicators. Neurosurgery 2014; 75(Suppl 1):S3-S15

11 Pryor RR, Casa DJ, Vandermark LW, et al. Athletic training services in public secondary schools: a benchmark study.J Athl Train 2015; 50(02):156-162

12 Sirmon-Taylor B, Salvatore AP. Consideration of the federal guidelines for academic services for student-athletes with sports-related concussion. Perspectives School Based Issues 2012;13:70-78

13 Krug H, Turkstra LS. Assessment of cognitive-communication disorders in adults with mild traumatic brain injury. Perspect Neurophysiol Neurogenic Speech Lang Disord 2015;25:17-35

14 American Speech-Language-Hearing Association. Evaluating and treating communication and cognitive disorders: Approaches to referral and collaboration for speech-language pathology and clinical neuropsychology [Technical Report], 2003. Available at: www.asha.org/policy. Accessed April 18, 2016

15 Ritchie LJ, Mrazik M, Alfano DP, et al. The role of neuropsychology in the management of youth concussion in Canada. Curr Res Concuss 2015;2(01):8-10

16 Duff MC, Stuck S. Paediatric concussion: Knowledge and practices of school speech-language pathologists. Brain Inj 2015;29(01): 64-77

17 Coelho CA. Management of discourse deficits following traumatic brain injury: progress, caveats, and needs. Semin Speech Lang 2007;28(02):122-135

18 Sohlberg MM, Mateer CA. Improving attention and managing attentional problems. Adapting rehabilitation techniques to adults with ADD. Ann N Y Acad Sci 2001;931:359-375 